BMJ Open Ophthalmology

\section{Virucidal benefits of povidone-iodine use on the ocular surface: a review}

To cite: Edington $M$, Ramaesh K, Lockington D. Virucidal benefits of povidone-iodine use on the ocular surface: a review. BMJ Open Ophthalmology 2020;5:e000509. doi:10.1136/ bmjophth-2020-000509

Received 12 May 2020 Revised 23 July 2020 Accepted 28 July 2020
Check for updates

\section{(c) Author(s) (or their} employer(s)) 2020. Re-use permitted under CC BY-NC. No commercial re-use. See rights and permissions. Published by BMJ.

Tennent Institute of Ophthalmology, Glasgow, United Kingdom

Correspondence to Dr Magdalena Edington; medington@nhs.net

\section{ABSTRACT}

Povidone-iodine (PVI) preparations are well known for their microbicidal effect. In ophthalmology, PVI is commonly used to sterilise the ocular surface prior to surgical procedures. It is also used uncommonly as treatment for adenoviral conjunctivitis, yet the virucidal benefits of PVI have not been clearly documented in existing clinical management guidelines for ocular surface conditions. The COVID-19 pandemic, caused by the novel severe acute respiratory syndrome coronavirus 2 (SARS-CoV-2) virus, has challenged traditional healthcare systems. The morbidity and mortality of this highly contagious disease have resulted in fatalities among healthcare workers, including ophthalmologists. The SARS-CoV-2 virus has been identified on conjunctival testing, a potential source of contagious infection which may be unrecognised in asymptomatic carriers. Concern has been raised that ocular procedures may be 'aerosol-generating' and the additional wearing of personal protective equipment has been recommended to protect operating theatre staff. This literature review demonstrates that PVI has a broad virucidal activity, including against coronaviruses. It is already used perioperatively as standard of ophthalmic care and has been shown clinically to be effective against adenoviruses on the ocular surface. The current surgical practice of application of $5 \%-10 \% \mathrm{PVI}$ applied periocularly for $3 \mathrm{~min}$ seems to provide an adequate effective reduction in the patient's ocular surface viral load. The virucidal benefits of routine PVI use should be included in ophthalmology guidelines regarding safe ocular surgery protocols.

\section{INTRODUCTION}

The severe acute respiratory syndrome coronavirus 2 (SARS-CoV-2) pandemic has caused significant disruption to routine ophthalmology services, including the suspension of all elective ophthalmic surgery. Recent guidelines on returning to surgical practice by the Royal College of Ophthalmologists have expressed concern that vitreoretinal and cataract surgeries may be 'aerosol-generating' and so recommend appropriate personal protective equipment use. ${ }^{2}$ However, these guidelines have not addressed the pre-existing benefits of povidone-iodine (PVI) application in protecting operating theatre personnel through sterilisation of the patient's ocular surface. The aim of this review was to present the evidence base for the virucidal effects of PVI, including against coronaviruses $(\mathrm{CoV})$, and evaluate whether the current surgical standard of topical application offers adequate reduction in viral load on the ocular surface.

\section{METHODS}

A Medline search was conducted on 20 April 2020. The following terms were used, always in combination with 'povidone iodine' (with number of articles found in parentheses): virus (115), virucidal (32), coronavirus (4), adenovirus (23), conjunctivitis (80). The authors then selected the articles which were relevant to PVI and the ocular surface. Both laboratory and clinical studies were evaluated. Identifying the lack of evidence supporting the anecdotal recommendations in current guidelines was the main catalyst for this review. We also wanted to evaluate the objective established literature regarding the virucidal effects of PVI, rather than the recent phenomenon of comment/correspondence opinion-based publications detailing COVID concerns.

\section{PROPERTIES OF PVI}

PVI preparations are well known to be effective against multiple bacteria, fungi and protozoa. They are also effective against both enveloped and non-enveloped viruses, but these benefits are less commonly recognised in the ophthalmic literature. PVI is thought to have a multimodal activity against pathogens, which includes oxidising vital structures such as amino acids, nucleotides and membrane components. ${ }^{3} 4$ Electron microscopic and biochemical observations support the conclusion that PVI interacts with cell walls of micro-organisms, causing pore formation or generating solid-liquid interfaces at the lipid membrane level, which lead to loss of cytosol material, in addition to enzyme denaturation. $^{5}$ There are limited data about the specific mode of action resulting in virucidal effect; however, work on the influenza virus by Sriwilaijaroen et al demonstrated that PVI inhibits viral haemagglutinin as well as 
neuraminidases by a mixed-type inhibition mechanism. ${ }^{6}$ The described beneficial sterilisation properties of PVI include broad antimicrobial spectrum, lack of emergence of resistance, ability to penetrate biofilms, low cytotoxicity to host cells, tolerability, cost-effectiveness and overall favourable risk/benefit profile. ${ }^{3}$ It is therefore unsurprising that PVI is commonly used for surgical sterilisation purposes of the ocular surface in ophthalmology.

\section{USE OF PVI ON THE OCULAR SURFACE IN OPHTHALMOLOGY}

The first studies on the application of diluted PVI solutions for conjunctival sac irrigation are dated to the 1960s. In current standard ophthalmic practice, PVI is commonly used for preparation and cleaning of the ocular surface, eyelids, eyelashes and conjunctiva prior to intraocular surgery or intravitreal injections (IVT) to decrease the risk of endophthalmitis. It has also been used effectively as both prophylaxis and treatment in ophthalmia neonatorum, and in the treatment of bacterial conjunctivitis, microbial keratitis, adenoviral conjunctivitis, giant fornix syndrome and in association with the Boston type I keratoprosthesis. $^{78}$

Numerous studies have demonstrated the effectiveness and safety of PVI in endophthalmitis prevention following intraocular procedures. Speaker and Menikoff's randomised study comparing 5\% PVI versus silver protein solution established the superiority of PVI in postoperative endophthalmitis prevention that led to a major shift in clinical practice. ${ }^{9}$ The importance of PVI use was further highlighted by Modjtahedi et al, when they reported an increased endophthalmitis rate of approximately $9.4 \%$ in patients undergoing IVT who did not receive PVI or alternative antiseptic due to selfreported iodine allergies. ${ }^{10}$ The effectiveness of PVI for ocular surface sterilisation has resulted in preprocedure antibiotics no longer being routinely recommended for cataract surgery or IVT. ${ }^{11-14}$

\section{CONCENTRATION AND EXPOSURE TIME}

There is some controversy about the optimum concentration and exposure time of PVI to achieve maximum effectiveness of sterilisation of the ocular surface. Microbicidal effect of PVI is achieved by free iodine molecules; these become inactivated on contact with a pathogen, and need to be replenished. The concentration of free iodine is $5 \mathrm{ppm}$ in a $10 \%$ PVI solution compared with $24 \mathrm{ppm}$ in a $0.1 \%$ solution; therefore, time required for microbicidal effect is shorter for $0.1 \%-1 \%$ PVI (15s) compared with $2.5 \%-10 \%$ PVI (30-120s). ${ }^{7}$ At lower concentrations PVI needs to be reapplied to sustain microbicidal effect, while the duration of activity of $2.5 \%-10 \%$ PVI is longer. This explains the findings of Ferguson et al who reported that, despite in vitro evidence of higher bactericidal activity of PVI at more dilute concentrations, 5\% PVI is more effective than $1 \%$ in decreasing the human conjunctival bacterial flora in vivo, particularly in the presence of heavier initial bacterial load. ${ }^{15}$ Guidelines vary for specific ophthalmic procedures; while the European Society of Cataract and Refractive Surgeons (ESCRS) prevention of endophthalmitis publication recommends 5\%-10\% PVI solution application to the cornea, conjunctival sac and periocular skin for a minimum of $3 \mathrm{~min}$ prior to surgery, ${ }^{12}$ an expert panel recommended only a $30 \mathrm{~s}$ application prior to IVT. ${ }^{16}$ It should be noted that these ESCRS prevention of endophthalmitis guidelines do not specifically address the virucidal properties of PVI for the ocular surface.

\section{PVI AND ADENOVIRUS}

Human adenovirus (HAdV) is the most common cause of infectious conjunctivitis, accounting for up to $75 \%$ of all conjunctivitis cases. ${ }^{17}$ Patients can develop a keratoconjunctivitis, with subepithelial corneal infiltrates that can cause long-term visual impairment. ${ }^{17}$ At least 19 different serotypes of HAdV have been associated with epidemic keratoconjunctivitis, with serotypes 8,19 and 37 being the most common. ${ }^{18}$ Persistent HAdV secretions in the tears may occur years following the resolution of acute ocular infection. ${ }^{17}$ There are currently no licensed treatments for adenoviral keratoconjunctivitis, with conservative management options such as cold compresses and artificial tears alleviating symptoms, rather than reducing viral shedding, which would limit severity and duration of infection.

PVI preparations have been shown to be effective against adenovirus in the laboratory. Sauerbrei et al studied the effect of biocides including PVI on inactivation of the genome of multiple HAdV serotypes; while PVI did not denature hexon protein or destroy the adenoviral genome, it reduced viral infectivity, indicating that the genomes of HAdV show more chemical resistance than the complete viral particle. ${ }^{1920}$ Monnerat et al investigated the effect of diluted PVI on free adenovirus and adenoviral infected cells. They reported that PVI at a concentration of 1:10 (0.8\%) completely extinguishes infectivity of free adenovirus after an exposure time of $10 \mathrm{~min}$ but is less effective against intracellular adenoviral particles in already infected cells. ${ }^{21}$ Akanuma evaluated the effect of PVI against HAdV using a real-time PCR method. PVI at $0.2 \%$ concentration was effective against HAdV-3, HAdV-4, HAdV-19 and HAdV-37 after $1 \mathrm{~min}$, and against HAdV-8 after $3 \mathrm{~min} .^{22}$ PVI has also been shown to demonstrate virucidal action against ocular HAdV types $3,4,5,7$ and 8 at $1-5 \mathrm{~min}$ and types 37 and 64 at 15-60 min for various concentrations. ${ }^{23}$ These studies may indicate that time of exposure, not concentration of PVI, is critical to disinfection. Additionally, Cheung et al demonstrated that multiple types of HAdV can be involved in a single outbreak; as PVI has virucidal activity against multiple serotypes, it could be an effective management option to decrease ocular surface viral load. ${ }^{24}$

Multiple clinical studies have proven the safety and tolerability of PVI in treating adenoviral conjunctivitis. ${ }^{25} 26$ A clinical trial looking at three drops of $0.5 \%$ PVI administered thrice daily (in combination with artificial tears at 
pH 4.2 for enhanced tolerability) found faster recovery from disease at 2 weeks compared with controls. ${ }^{27}$ Similarly, Özen Tunay et al evaluated the effect of conjunctival irrigation with $2.5 \%$ PVI in infantile adenoviral conjunctivitis, and observed statistically significant lower clinical scores and faster recovery time in the group treated with PVI compared with control. ${ }^{28}$ Hutter found that, compared with other treatments, PVI was most effective in reducing the severity of HAdV-8 conjunctivitis, although it did not completely prevent formation of subepithelial infiltrates. ${ }^{29}$ Altan-Yaycioglu et al noticed that while the clinical severity of keratoconjunctivitis was similar, there was a significant decrease in the incidence of subepithelial infiltrates in patients who used 2\% PVI compared with controls. ${ }^{30}$ Combination treatment with dexamethasone has also been investigated and demonstrated faster resolution and significant reduction in viral titre compared with controls. ${ }^{31-36}$

\section{PVI AND CORONAVIRUS}

Coronaviruses $(\mathrm{CoVs})$ are single-stranded RNA viruses belonging to the family Coronaviridae. They have a characteristic structure of surface projections on the viral envelope, giving them a crown appearance. There are seven types of CoVs known to infect humans; the most infamous are Middle East respiratory syndrome coronavirus (MERS-CoV), SARS-CoV and the most recent SARS-CoV-2 (causing the COVID-19 pandemic). ${ }^{37}$ These CoVs can be transmitted by a mixture of aerosol, droplets and direct contact, and cause respiratory tract infections with a wide spectrum of clinical manifestations. ${ }^{38}$ After infection, significant increases in neutralising antibody titre have been found in nasal secretions and serum; however, it is possible to be reinfected with the same $\mathrm{CoV}$ soon after recovery. ${ }^{39}$ While most CoV infections are mild and self-limiting, SARS-CoV, MERS-CoV and SARS-CoV-2 have high morbidity and mortality.

CoVs have been known to cause a wide spectrum of ocular infections in animals, including conjunctivitis, anterior uveitis, retinitis and optic neuritis. ${ }^{37}$ There are limited data on the ophthalmological associations of human $\mathrm{CoV}$ infections, but there have been case reports of conjunctivitis in CoV-positive patients, as well as a case series showing the presence of SARS-CoV RNA in tears. ${ }^{404}$ This could have serious implications for ophthalmologists operating on potentially infectious patients during and after the SARS-CoV-2 pandemic.

In their review, Seah and Agrawal advised that ophthalmologists and other healthcare workers should err on the side of caution to prevent the possible transmission of CoVs through ocular tissue. ${ }^{37} \mathrm{Du}$ et al described the protective measures of emergency ophthalmic surgery for medical staff, patients, environment and instruments at Tongji Hospital during the SARS-CoV-2 pandemic, which resulted in zero infection at the time of publication. These included N95 masks, double gloves, protective clothing and goggles worn by surgeons, and masks worn by patients in theatre. ${ }^{42}$ As concern has been raised regarding the potential for ophthalmic procedures such as cataract surgery and trabeculectomy to be considered 'aerosol-generating', questions exist regarding the best means of protection of patients and staff from $\mathrm{CoV}$ during ophthalmic surgery.

Dexter et al described an evidence-based approach for optimisation of infection control and operating room management from the anaesthetic point of view. Specifically, they recommend decolonising patients using preprocedural chlorhexidine wipes, two doses of nasal PVI within 1 hour of incision and chlorhexidine mouth rinse. $^{43}$

Eggers et al tested the in vitro efficacy of three formulations of PVI (4\% skin cleanser, $7.5 \%$ surgical scrub and $1 \%$ gargle/mouthwash, each with brand name Betadine) against a reference virus (modified vaccinia virus Ankara; MVA) and MERS-CoV. They achieved viral titre reduction of $>99.99 \%$ versus both MVA and MERS-CoV, under both clean and dirty conditions, within $15 \mathrm{~s}$ of application of each undiluted PVI product, and within $15-30 \mathrm{~s}$ at 1:10 dilution. ${ }^{44}$ Kariwa et al tested the efficacy of several PVI products against SARS-CoV in the laboratory, covering a variety of disinfection applications. All PVI products reduced infectivity of SARS-CoV to below detectable levels within 2 min of exposure. ${ }^{45}$ Kampf et al analysed the inactivation of CoVs by biocidal agents in suspension tests, and found that PVI $(0.23 \%-7.5 \%)$ readily inactivated $\mathrm{CoV}$ infectivity by $4 \log _{10}$ or more. ${ }^{46}$ There is a lack of in vivo studies on the effectiveness of PVI on CoVs.

\section{PVI AND OTHER VIRUSES}

Kawana et al compared PVI's virucidal action to other antiseptics in inactivating a broad range of both enveloped and non-enveloped viruses (adenovirus, mumps, rotavirus, poliovirus, coxsackievirus, rhinovirus, herpes simplex virus, rubella, measles, influenza and HIV) in vitro, and demonstrated PVI to have the broadest spectrum of antiviral activity among agents tested ${ }^{47}$ Sauerbrei and Wutzler reported that PVI has virucidal efficacy against most enveloped and non-enveloped viruses within $5 \mathrm{~min}$ and additionally has a synergistic virucidal effect when combined with alcohol-based disinfectants. ${ }^{48}$ Other studies confirmed the effectiveness of PVI against the viruses already mentioned, but different concentrations and exposure times were required. ${ }^{49-53}$

Similarly, Sokal and Hermonat demonstrated 90\% inactivation of papillomavirus with exposure to $0.1 \%$ PVI, and $99.9 \%$ inactivation at concentration of $0.3 \% .^{54}$ PVI was also found to be effective against human cytomegalovirus, ${ }^{55}$ murine norovirus ${ }^{56}$ and both human and avian influenza viruses. ${ }^{67}$ A study by Eggers $e t$ al showed that Ebola and MVA titres were reduced by $>99.99 \%$ to $>99.999 \%$ under both clean and dirty conditions after exposure to PVI for $15 \mathrm{~s} .^{58}$ Lastly, studies have confirmed the effectiveness of PVI solutions against HIV, although the tested concentrations and time of exposure differed, highlighting that this could have a significant effect on the virucidal activity of PVI. ${ }^{5-61}$ 


\section{PVI RELEVANCE TO CURRENT OPHTHALMIC PRACTICE}

The SARS-CoV-2 pandemic has caused significant disruption to routine ophthalmology services. Reinstating elective surgical lists carries the challenge of minimising the viral load of confirmed cases as well as of asymptomatic SARS-CoV-2 carriers in order to protect surgical staff. While there is a lack of published clinical evidence on the effect of PVI preparations against CoVs in ophthalmic surgery, in vitro studies show potent virucidal activity, including against MERS and SARS. Specifically, PVI formulations have elicited $\mathrm{CoV}$ inactivation of $>99.99 \%$ in test systems, in some cases occurring as quickly as within $15 \mathrm{~s}$ of contact. There is ongoing controversy about the concentration of PVI and time of exposure required for adequate reduction of microbial load. In current practice, a concentration of $5 \%-10 \% \mathrm{PVI}$ applied for $3 \mathrm{~min}$ is deemed to be sufficient for procedures such as cataract surgery to prevent endophthalmitis. Further studies on the effect of PVI concentration and exposure time on reduction of viral load in vivo are required; however, the presented literature provides a reassuring evidence base to persist with the current PVI regime in ocular surgery during and after COVID-19.

\section{LIMITATIONS}

This review presents the established evidence base documenting the beneficial virucidal properties of PVI in relation to the ocular surface. These indications fall into two main categories-as a preventive antiseptic, and as a therapeutic adjunctive agent in the treatment of virusbased ocular surface conditions. Both these roles predate the current context of COVID-19. As historic (ESCRS prevention of endophthalmitis) and current (COVID-19) publications do not specifically comment on the potential benefits of PVI, we wished to review and document the objective literature. Since the date of our literature search and our original submission, there has been an abundance of articles and recommendations directly relating to $\mathrm{CoV}$, across multiple specialties (including anaesthetics, dentistry, ear, nose and throat, and maxillofacial surgery). The majority of these are opinion-based comment and correspondence publications. Such recommendations include the use of PVI as an antiseptic mouthwash, skin wash and nasal spray to help decolonise patients potentially infected with COVID-19. These articles, however, are outside the scope of this review, which deals specifically with the evidence for PVI use on the ocular surface in ophthalmology.

As previously highlighted, there is limited clinical evidence as to the exact virucidal mechanism of action of PVI preparations, their specific effect on CoVs, as well as the exact concentration and exposure time required for optimal virucidal activity; further studies in vivo are required. This review focused only on virucidal activity on the ocular surface in established ophthalmic practice. The published evidence would suggest that the common current preprocedure surgical use of 5\%-10\% PVI applied for 3 min seems to provide an adequate reduction in ocular surface viral load, particularly for short cases such as IVT or cataract. However, it is not clear how alterations in surgical behaviour, such as further ocular surface and/or fornix irrigation, may influence this sterilising virucidal effect. Equally, the potential for virus to reform on the ocular surface potentially from a colonised lacrimal sac secretion during prolonged surgery has not been definitely addressed in the literature. While some clinicians may be tempted to reapply PVI to the ocular surface during ophthalmic surgical cases of longer duration, there is no clinical evidence to either support or refute that practice.

\section{CONCLUSION}

The review demonstrates that PVI has a broad virucidal activity, and is both effective and safe when applied to the ocular surface. It is already used for ocular surface disinfection as the current standard of care prior to minor ocular surface procedures (such as suture removal), refractive and intraocular procedures. In addition to being effective against adenoviruses on the ocular surface, PVI's properties have been used in ophthalmology in the prophylaxis and treatment of conditions such as ophthalmia neonatorum, bacterial conjunctivitis, microbial keratitis and giant fornix syndrome. It may prove to have wider clinical applications in the future, including the management of eye casualty patients presenting with suspected viral conjunctivitis. The current surgical application of 5\%-10\% PVI applied for 3 min seems to provide an adequate reduction in viral load, particularly for short cases such as IVT or cataract. It is unclear how long the virucidal effect lasts in the real-world surgical scenario. PVI use does not remove the requirement for appropriate safety measures such as wearing of personal protective equipment by both theatre staff and patients to protect from infectious cases of COVID-19. However, the virucidal benefits of routine PVI use should be recognised and acknowledged in ophthalmology guidelines regarding safe ocular surgery.

Contributors ME: planning, literature search, manuscript preparation. KR: manuscript preparation and editing. DL: planning, editing, guarantor of overall content.

Funding The authors have not declared a specific grant for this research from any funding agency in the public, commercial or not-for-profit sectors.

Competing interests None declared.

Patient consent for publication Not required.

Provenance and peer review Not commissioned; externally peer reviewed.

Open access This is an open access article distributed in accordance with the Creative Commons Attribution Non Commercial (CC BY-NC 4.0) license, which permits others to distribute, remix, adapt, build upon this work noncommercially, and license their derivative works on different terms, provided the original work is properly cited, appropriate credit is given, any changes made indicated, and the use is non-commercial. See: http://creativecommons.org/ licenses/by-nc/4.0/.

\section{ORCID iDs}

Magdalena Edington http://orcid.org/0000-0002-6905-8396

David Lockington http://orcid.org/0000-0001-7984-0958 


\section{REFERENCES}

1 Royal College of Ophthalmologists. Cataract surgery during the COVID-19 pandemic, 2020. Available: https://www.rcophth.ac. uk/wp-content/uploads/2020/04/RCOphth-UKISCRS-COVIDcataract-surgery-guidance-FINAL-170420.pdf [Accessed 5 May 2020].

2 Royal College of Ophthalmologists. Reopening and redeveloping ophthalmology services during Covid recovery - interim guidance, 2020. Available: https://www.rcophth.ac.uk/wp-content/uploads/ 2020/04/Reopening-and-redeveloping-ophthalmology-servicesduring-Covid-recovery-Interim-guidance-1.pdf [Accessed 5 May 2020].

3 Bigliardi PL, Alsagoff SAL, El-Kafrawi HY, et al. Povidone iodine in wound healing: a review of current concepts and practices. Int $J$ Surg 2017;44:260-8.

4 Eggers M. Infectious disease management and control with povidone iodine. Infect Dis Ther 2019;8:581-93.

5 Schreier H, Erdos G, Reimer K, et al. Molecular effects of povidoneiodine on relevant microorganisms: an electron-microscopic and biochemical study. Dermatology 1997;195(Suppl 2):111-6.

6 Sriwilaijaroen N, Wilairat $\mathrm{P}$, Hiramatsu $\mathrm{H}$, et al. Mechanisms of the action of povidone-iodine against human and avian influenza $A$ viruses: its effects on hemagglutination and sialidase activities. Viro J 2009;6:124.

7 Grzybowski A, Kanclerz P, Myers WG. The use of povidone-iodine in ophthalmology. Curr Opin Ophthalmol 2018;29:19-32.

8 Isenberg SJ, Apt L, Campeas D. Ocular applications of povidoneiodine. Dermatology 2002;204(Suppl 1):92-5.

9 Speaker MG, Menikoff JA. Prophylaxis of endophthalmitis with topical povidone-iodine. Ophthalmology 1991;98:1769-75.

10 Modjtahedi BS, van Zyl T, Pandya HK, et al. Endophthalmitis after intravitreal injections in patients with self-reported iodine allergy. Am J Ophthalmol 2016;170:68-74.

11 Grzybowski A, Turczynowska M. Standard preoperative topical antibiotics do not additionally benefit in postcataract endophthalmitis prophylaxis. J Cataract Refract Surg 2017;43:861-2.

12 Barry P, Cordoves L, Susanne G. ESCRS guidelines for prevention and treatment of endophthalmitis following cataract surgery: data dilemmas and conclusions, 2013. Available: https://www.escrs.org/ downloads/Endophthalmitis-Guidelines.pdf [Accessed 5 May 2020].

13 Halachmi-Eyal O, Halachimi-Eyal O, Lang Y, et al. Preoperative topical moxifloxacin $0.5 \%$ and povidone-iodine $5.0 \%$ versus povidone-iodine $5.0 \%$ alone to reduce bacterial colonization in the conjunctival sac. J Cataract Refract Surg 2009;35:2109-14.

14 Li AL, Wykoff CC, Wang R, et al. Endophthalmitis after intravitreal injection: role of prophylactic topical ophthalmic antibiotics. Retina 2016;36:1349-56.

15 Ferguson AW, Scott JA, McGavigan J, et al. Comparison of 5\% povidone-iodine solution against $1 \%$ povidone-iodine solution in preoperative cataract surgery antisepsis: a prospective randomised double blind study. Br J Ophthalmol 2003;87:163-7.

16 Avery RL, Bakri SJ, Blumenkranz MS, et al. Intravitreal injection technique and monitoring: updated guidelines of an expert panel. Retina 2014;34:1-18.

17 Labib BA, Minhas BK, Chigbu DI. Management of adenoviral keratoconjunctivits: challenges and solutions. Clin Ophthalmol 2020;17:837-52.

18 Letko E. Nosocomial adenovirus keratoconjunctivitis. $\mathrm{Br} \mathrm{J}$ Ophthalmol 2009;93:3.

19 Sauerbrei A, Sehr K, Eichhorn U, et al. Inactivation of human adenovirus genome by different groups of disinfectants. J Hosp Infect 2004:57:67-72.

20 Sauerbrei A, Eichhorn U, Scheibenzuber M, et al. Hexon denaturation of human adenoviruses by different groups of biocides. $J$ Hosp Infect 2007;65:264-70.

21 Monnerat N, Bossart W, Thiel MA. [Povidone-iodine for treatment of adenoviral conjunctivitis: an in vitro study]. Klin Monbl Augenheilkd 2006;223:349-52.

22 Akanuma M. [Evaluation of disinfectant against adenovirus by real-time polymerase chain reaction]. Nippon Ganka Gakkai Zasshi 2007;111:384-90

23 Yates KA, Shanks RMQ, Kowalski RP, et al. The in vitro evaluation of povidone-iodine against multiple ocular adenoviral types. J Ocul Pharmacol Ther 2019;35:132-6.

24 Cheung D, Bremner J, Chan JTK. Epidemic kerato-conjunctivitis--do outbreaks have to be epidemic? Eye 2003;17:356-63.

25 Shorter E, Whiteside M, Harthan J, et al. Safety and tolerability of a one-time, in-office administration of $5 \%$ povidone-iodine in the treatment of adenoviral conjunctivitis: The Reducing Adenoviral Patient Infected Days (RAPID) study. Ocul Surf 2019;17:828-32.
26 Trinavarat A, Atchaneeyasakul L-O. Treatment of epidemic keratoconjunctivitis with $2 \%$ povidone-iodine: a pilot study. $\mathrm{J}$ Ocul Pharmacol Ther 2012;28:53-8.

27 Yazar H, Yarbag A, Balci M, et al. The effects of povidone iodine (pH 4.2) on patients with adenoviral conjunctivitis. J Pak Med Assoc 2016;66:968-70.

28 Özen Tunay Z, Ozdemir O, Petricli IS. Povidone iodine in the treatment of adenoviral conjunctivitis in infants. Cutan Ocul Toxicol 2015;34:12-15.

29 Hutter $\mathrm{H}$. [Epidemic keratoconjunctivitis: treatment results during an epidemic]. Klin Monbl Augenheilkd 1990;197:214-7.

30 Altan-Yaycioglu R, Sahinoglu-Keskek N, Canan H, et al. Effect of diluted povidone iodine in adenoviral keratoconjunctivitis on the rate of subepithelial corneal infiltrates. Int $J$ Ophthalmol 2019;12:1420-5.

31 Clement C, Capriotti JA, Kumar M, et al. Clinical and antiviral efficacy of an ophthalmic formulation of dexamethasone povidoneiodine in a rabbit model of adenoviral keratoconjunctivitis. Invest Ophthalmol Vis Sci 2011;52:339-44.

32 Pepose JS, Ahuja A, Liu W, et al. Randomized, controlled, phase 2 trial of Povidone-lodine/Dexamethasone ophthalmic suspension for treatment of adenoviral conjunctivitis. Am J Ophthalmol 2018;194:7-15

33 Pepose JS, Narvekar A, Liu W, et al. A randomized controlled trial of povidone-iodine/dexamethasone ophthalmic suspension for acute viral conjunctivitis. Clin Ophthalmol 2019;13:535-44.

34 Pinto RDP, Lira RPC, Abe RY, et al. Dexamethasone/Povidone eye drops versus artificial tears for treatment of presumed viral conjunctivitis: a randomized clinical trial. Curr Eye Res 2015;40:870-7.

35 Kovalyuk N, Kaiserman I, Mimouni M, et al. Treatment of adenoviral keratoconjunctivitis with a combination of povidone-iodine $1.0 \%$ and dexamethasone $0.1 \%$ drops: a clinical prospective controlled randomized study. Acta Ophthalmol 2017;95:e686-92.

36 Pelletier JS, Stewart K, Trattler W, et al. A combination povidoneiodine $0.4 \%$ /dexamethasone $0.1 \%$ ophthalmic suspension in the treatment of adenoviral conjunctivitis. Adv Ther 2009;26:776-83.

37 Seah I, Agrawal R. Can the coronavirus disease 2019 (COVID-19) affect the eyes? A review of coronaviruses and ocular implications in humans and animals. Ocul Immunol Inflamm 2020;28:391-5.

38 Eggers M, Koburger-Janssen T, Eickmann M, et al. In Vitro Bactericidal and Virucidal Efficacy of Povidone-lodine Gargle/ Mouthwash Against Respiratory and Oral Tract Pathogens. Infect Dis Ther 2018;7:249-59.

39 Holmes KV. SARS coronavirus: a new challenge for prevention and therapy. J Clin Invest 2003;111:1605-9.

40 Vabret A, Mourez T, Dina J, et al. Human coronavirus NL63, France. Emerg Infect Dis 2005;11:1225-9.

41 Loon S-C, Teoh SCB, Oon LLE, et al. The severe acute respiratory syndrome coronavirus in tears. Br J Ophthalmol 2004;88:861-3.

$42 \mathrm{Du} \mathrm{H}$, Zhang M, Zhang $\mathrm{H}$, et al. Practical experience on emergency ophthalmic surgery during the prevalence of COVID-19. Graefes Arch Clin Exp Ophthalmol 2020;258:1831-3.

43 Dexter F, Parra MC, Brown JR, et al. Perioperative COVID-19 defense: an evidence-based approach for optimization of infection control and operating room management. Anesth Analg 2020;131:37-42.

44 Eggers M, Eickman M, Zorn J. Rapid and effective virucidal activity of povidone-iodine products against middle East respiratory syndrome coronavirus (MERS-CoV) and modified vaccinia virus Ankara (MVA). Infect Dis Ther 2018;7:235-47.

45 Kariwa H, Fujii N, Takashima I. Inactivation of SARS coronavirus by means of povidone-iodine, physical conditions and chemical reagents. Dermatology 2006;212(Suppl 1):119-23.

46 Kampf G, Todt D, Pfaender S, et al. Persistence of coronaviruses on inanimate surfaces and their inactivation with biocidal agents. $J$ Hosp Infect 2020;104:246-51.

47 Kawana R, Kitamura T, Nakagomi O, et al. Inactivation of human viruses by povidone-iodine in comparison with other antiseptics. Dermatology 1997;195(Suppl 2):29-35

48 Sauerbrei A, Wutzler P. Virucidal efficacy of povidone-iodinecontaining disinfectants. Lett Appl Microbiol 2010;51:158-63.

49 Wutzler P, Sauerbrei A, Klöcking R, et al. Virucidal and chlamydicidal activities of eye drops with povidone-iodine liposome complex. Ophthalmic Res 2000;32:118-25.

50 Wutzler P, Sauerbrei A, Klöcking R, et al. Virucidal activity and cytotoxicity of the liposomal formulation of povidone-iodine. Antiviral Res 2002:54:89-97.

51 Reimer K, Wichelhaus TA, Schäfer V, et al. Antimicrobial effectiveness of povidone-iodine and consequences for new application areas. Dermatology 2002;204(Suppl 1):114-20. 
52 Wada H, Nojima Y, Ogawa S, et al. Relationship between virucidal efficacy and free iodine concentration of povidone-iodine in buffer solution. Biocontrol Sci 2016;21:21-7.

53 Benevento WJ, Murray P, Reed CA, et al. The sensitivity of Neisseria gonorrhoeae, Chlamydia trachomatis, and herpes simplex type II to disinfection with povidone-iodine. Am J Ophthalmol 1990;109:329-33.

54 Sokal DC, Hermonat PL. Inactivation of papillomavirus by low concentrations of povidone-iodine. Sex Transm Dis 1995;22:22-4.

55 Numazaki K, Asanuma H. Inhibitory effect of povidone-iodine for the antigen expression of human cytomegalovirus. In Vivo 1999;13:239-41.

56 Matsuhira T, Kaji C, Murakami S, et al. Evaluation of four antiseptics using a novel murine norovirus. Exp Anim 2012;61:35-40.
57 Ito $\mathrm{H}$, Ito $\mathrm{T}$, Hikida $\mathrm{M}$, et al. Outbreak of highly pathogenic avian influenza in Japan and anti-influenza virus activity of povidone-iodine products. Dermatology 2006;212(Suppl 1):115-8.

58 Eggers M, Eickmann M, Kowalski K, et al. Povidone-iodine hand wash and hand rub products demonstrated excellent in vitro virucidal efficacy against Ebola virus and modified vaccinia virus Ankara, the new European test virus for enveloped viruses. BMC Infect Dis 2015;15:375.

59 Shimakoshi Y, Sano K, Nakano T, et al. A micro-suspension-test for evaluation of disinfectants against human immunodeficiency virus. Kansenshogaku Zasshi 1995;69:532-8.

60 Harbison MA, Hammer SM. Inactivation of human immunodeficiency virus by Betadine products and chlorhexidine. J Acquir Immune Defic Syndr 1989;2:16-20.

61 Kaplan JC, Crawford DC, Durno AG, et al. Inactivation of human immunodeficiency virus by Betadine. Infect Control 1987;8:412-4. 